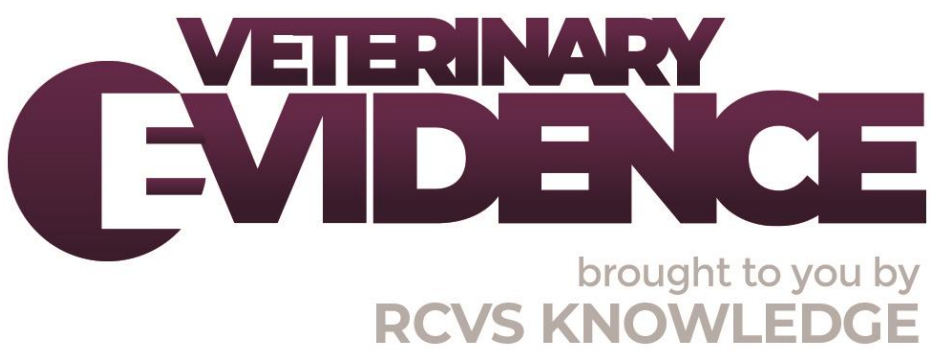

\title{
Thank you to our 2021 reviewers
}

Dr Kit Sturgess MA VetMB PhD CertVR DSAM CertVC FRCVS ${ }^{1 *}$

\footnotetext{
${ }^{1}$ Vet Freedom Ltd Brockenhurst, Hampshire, SO42 70T

*Corresponding Author (kit.sturgess@btopenworld.com)
}

ISSN: 2396-9776

Published: 21 Jan 2022

in: Veterinary Evidence Vol 7, Issue 1

DOI: https://doi.org/10.18849/ve.v7i1.562 
As 2021 draws to a close I suspect few of us could have foreseen the past year. In the early part of the year, as COVID-19 vaccination gathered pace, like many, I was hopeful that we would be seeing coronavirus in the rearview mirror by the end of the year - only then to find ourselves in the midst of another wave of cases.

Despite all the headwinds of coronavirus and the impact of working from home, Veterinary Evidence has continued to flourish, publishing more papers this year than last. Published papers have covered an amazing range of different topics, illustrating not just the wide diversity of questions that are being answered, but the depth and breadth of the team of reviewers that give their time to extend veterinary knowledge, supported by a dedicated group of assistant editors and staff at the journal who coordinate activity, ensure standards, and continue to develop the journal.

As a journal, Veterinary Evidence is maturing with two of the main focuses this year being to further develop our internal journal systems - which has allowed us to apply for membership of COPE (Committee on Publication Ethics) - and work towards improving the discoverability and accessibility of our published papers. In order to achieve this, the team is working hard to redesign our current website and fulfil the criteria for inclusion in other citation databases beyond CAB Abstracts, such as Medline.

We have been delighted this year to expand our Editorial Board ensuring, as the journal grows, we have the necessary range of skills on the Board to maintain high quality, effective reviews delivered in a timely manner. I would like to take this opportunity to thank all our reviewers and everyone who has served on the Board this year for their tireless efforts on behalf of Veterinary Evidence - without your support the journal could not exist. This year the Board has had three online meetings, more than ever before, which have been essential in helping develop the strategy for Veterinary Evidence over the coming years, expanding the influence and reach of the journal with various strategic initiatives. Other key areas have included developing our policy on standard terminology, looking at the best ways to ensure Knowledge Summaries remain current and working towards making editorial decisions as consistent as possible.

And finally... a huge thank you to everyone who works for and supports Veterinary Evidence, wishing you all a safe and productive 2022.

\title{
Kit Sturgess
}

Editor-in-Chief

\author{
Adewole Adekola \\ Jane Alexander \\ Fergus Allerton \\ Elizabeth Baines \\ Simon Bate \\ Julia Beatty \\ Jackie Brearley \\ Jenny Brown \\ Louise Buckley \\ John Campbell \\ Hilary Causer
}


Peter Cockcroft

Jacqueline Cole

Francesca Compostella

Rachel Conwell

Claire Corridan

Amanda Curtis

Michael DeCozar

Laura Dixon

Sam Double

Tom Dutton

Jacklyn Ellis

Virginia Fajt

Myra Forster-van Hijfte

Merran Govendir

John Hird

Joanne Ireland

Anji Jonas

Theodora K. Tsouloufi

Sarah Keir

Latifa Khenissi

Clare Knottenbelt

Dave Leicester

Zofia Lisowski

Kate Loomes

Panos Loukopoulos

Tim Mair

Tristen Merlin

Andy Morris

Diego Moya Fernandez

John Munday

Malcolm Ness

Constance Neville White

Kazuya Oikawa

Maureen O'Mara

Catherine Oxtoby

April Paul

Catrina Pennington

Robert Pettitt

Kirstie Pickles

Brian Pound

David Ramey

Nicki Reed

David Rendle

lain Richards

Suzanne Rogers

Rebecca Schofield

Mark Senior

Gonçalo Serrano

Tom Shaw

Josh Slater

Lesca Sofyan 
Eva Spada

Mike Steele

Adam Swallow

James Swann

Faye Swinbourne

Sam Taylor

Christopher Thom

David Thomas

Tom Towers

Nieky van Veggel

Elke Van der Vekens

Kate Walters

Richard White

Adele Williams 


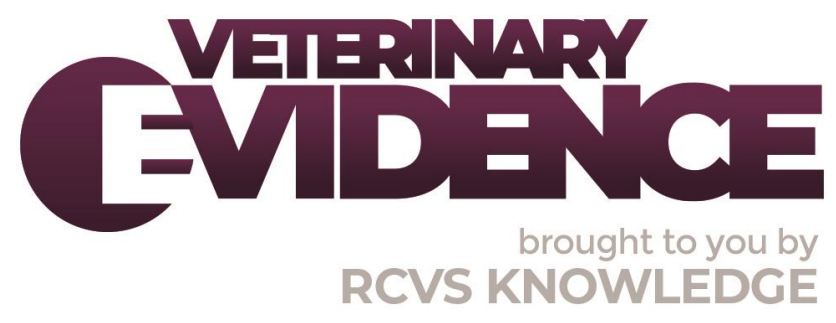

\section{Intellectual Property Rights}

Authors of Knowledge Summaries submitted to RCVS Knowledge for publication will retain copyright in their work, and will be required to grant RCVS Knowledge a non-exclusive license of the rights of copyright in the materials including but not limited to the right to publish, re-

publish, transmit, sell, distribute and otherwise use the materials in all languages and all media throughout the world, and to license or permit others to do so.

\section{Disclaimer}

Any opinions expressed in articles and other publication types published in Veterinary Evidence are the author's own and do not necessarily reflect the view of the RCVS Knowledge. Veterinary Evidence is a resource to help inform, and the content herein should not override the responsibility of the practitioner. Practitioners should also consider factors such as individual clinical expertise and judgement along with patient's circumstances and owners' values. Authors are responsible for the accuracy of the content. While the Editor and Publisher believe that all content herein are in accord with current recommendations and practice at the time of publication, they accept no legal responsibility for any errors or omissions, and make no warranty, express or implied, with respect to material contained within.

For further information please refer to our Terms of Use.

RCVS Knowledge is the independent charity associated with the Royal College of Veterinary Surgeons (RCVS). Our ambition is to become a global intermediary for evidence based veterinary knowledge by providing access to information that is of immediate value to practicing veterinary professionals and directly contributes to evidence based clinical decision-making.

https://www.veterinaryevidence.org/

RCVS Knowledge is a registered Charity No. 230886.

Registered as a Company limited by guarantee in England and Wales No. 598443.

Registered Office: Belgravia House, 62-64 Horseferry Road, London SW1P 2AF

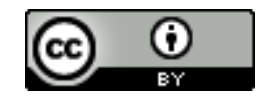

This work is licensed under a Creative Commons Attribution 4.0 International License. 